\title{
Legal Protection for Nurses in Providing Service to Patients
}

\author{
Yulianti Wulandari ${ }^{1}$, Rineke Sara $^{2}$ \\ \{wulanunborr@gmail.com ${ }^{1}$,rineke_sara@borobudur.ac.id ${ }^{2}$ \} \\ Universitas Borobudur, Jakarta, Indonesia ${ }^{1,2}$
}

\begin{abstract}
This review means to portray the lawful insurance for attendants in offering types of assistance to patients. By utilizing regularizing juridical exploration techniques followed by writing information assortment, it came about that medical attendants have been secured by appropriate laws. Law of Republic Indonesia No. 36 Year 2009 on wellbeing and negative. 39 of Nursing has managed the informational and delegative power assignment.
\end{abstract}

Keywords: Nurses; Patients; Legal protection

\section{Introduction}

Doctors and nurses are the closest health workers as implementers in providing health services to patients in hospitals and other health care facilities to heal patients. The power of specialists in doing their obligations and callings is normatively directed in the Law of the Republic of Indonesia Number 29 Year 2004 worried on Medical Practice. In the mean time, the Law of the Republic of Indonesia Number 38 Year 2014 on nursing directs attendants' clout in completing their obligations and callings. The guideline controls their freedoms and commitments as indicated by the area of science and capability.[1]

Doctors and nurses are two complementary professions, so nurses cannot work without collaborating with doctors. The collaborative relationship between doctors and nurses will be well established if carried out according to professional standards. However, a problem may occur from this collaborative relationship that can harm doctors, nurses, and patients.[2] One of the problems which may occur in collaborative relationships between doctors and nurses is that nurses often only carry out doctor's orders without paying attention to the comprehensible authority with the extent to which the nurse is allowed to perform the actions ordered by the doctor. The nurse's actions in carrying out orders from doctors are regulated in the law on nursing in the Articles 29 and 32 of Law number 38 Year 2014 of the nurses' delegation of authority for medical actions. The delegation of authority given by doctors to nurses can be in the form of a delegative authority delegation or a mandate which must be given in writing form. the delegation of authority that does not follow the existing norms can lead to arbitrary actions by health workers, doctors, nurses, and other health workers, resulting in negligence in carrying out medical actions called malpractice, which results in disability or death of the patient.[3]

However, the nursing profession is still under-recognized and receives less attention in the world of health. Based on these conditions, the presence of nurses is crucial in health services. 
The reason is the number of doctors that are not comparable to nurses, the restrictions on the practice of doctors, and the implementation of regional autonomy. In view of the Article 37 passage (2) on the clinical specialize in legal matters and Article 4 of the wellbeing pastor guideline number 512/Menkes/Per/IV/2007 concerning practice licenses and execution of clinical practices, a specialist's training grant is just allowed for a limit of three spots, in particular government-possessed wellbeing administration offices, exclusive medical services offices, and individual practices.

These conditions that affect the nurse's welfare and rights have not been fully considered so that lawsuits often arise and are addressed directly to nurses.[4] The lawsuit arose because the nurse was carrying out nursing care outside her authority. Moreover, it was due to unclear authority arrangements and delegation. Moreover, there was no lawful security for medical attendants in completing their calling that brought about unlawful activities taken by medical caretakers, including the commitment of medical caretakers to help crisis patients, which actually causes contention. This review means to depict the lawful insurance for medical caretakers in offering types of assistance to patients.

\section{Research Method}

This study uses a normative legal type of research. [5] The problem approach used the applicable law and conceptual approach by analyzing a problem that will be discussed through legal concepts from journals, books, and literature. In this study, the method of collecting legal materials used a library research technique which is a form of research by examining, collecting, and or browsing documents or literature that can provide information or information needed for this research.[6] The presentation is done by descriptive analysis by analyzing legal materials_through a systematically compiling.

\section{Discussion}

Wellbeing laborers play a significant part in endeavors to work on the nature of wellbeing administrations, as per the current laws and guidelines. The wellbeing laborers being referred to are specialists, medical caretakers, birthing assistants, drug specialists, and others. Medical caretakers in completing nursing works on, following the Article 29 (1) Law of the Republic of Indonesia Number 38 of 2014 concerning nursing, [3] have duties as implementing nursing care, providing guidance and counseling to patients, conducting research in the field of nursing, and carrying out tasks based on the authority delegation and as an executor of duties in certain circumstances. In addition, nurses also have three functions. First, nurses have an independent function where they can take independent actions. It means that nurses have obtained the authority through a law to provide health services in terms of nursing practice independently. Second, nurses take collaborative actions as an interpendent function. they work with other health workers, where nurses are jointly responsible with other health workers for the actions of health services provided to patients. The third function is the dependent function where nurses take actions to assist doctors in providing health services in the form of medical actions that should be the doctor's authority. The form of authority in this function is obtained through the mandate of authority delegation by doctors.[4] In this explanation, it is understandable that nurses as implementers of nursing practice have tasks that can be done 
alone, some tasks are carried out by the delegation of authority from doctors, and some tasks are carried out in collaboration with other health workers.[7]

The assignment of power identified with wellbeing laborers is managed in Article 65 of the Health Law Number 36 the Year 2014 on Health Workers and in the Law of the Republic of Indonesia Number 38 of 2014 on Nursing. Article 32 clarified that the appointment of power of clinical faculty to medical caretakers is given uniquely recorded as a hard copy, can be as a representative or an order. In the delegative power appointment, the designated task is trailed by the assigned liabilities. Then again, the appointment of assignments isn't trailed by the designation of obligations in the commanded appointment of power, which implies that the obligation is still with the order provider.

As a wellbeing laborer in doing their obligations, it won't just function true to form, there will be an issue that might emerge. Along these lines, lawful assurance is needed as a type of lawful conviction. The public authority's legitimate insurance for medical caretakers is managed in Article 27 of the Law of the Republic of Indonesia Number 36 the Year 2009 and Article 36 which expresses that attendants are qualified for lawful security as long as they do their obligations keeping administration guidelines, proficient principles, standard working methods, and legal arrangements. The public authority's legitimate insurance for attendants is as preventive lawful security that forestalls debates through the issuance of law on enlistment and nursing practice contained in the wellbeing act. It expresses that each medical caretaker who needs to work on nursing in medical services offices is needed to have practice consent, attendants and work grants, and oppressive lawful assurance that prompts debate goal. The oppressive legitimate insurance given by the public authority is as the use of debates through the overall court in case of misbehavior by specialists or medical caretakers.

Hypothetically, there are no less than three fundamental capacities that should be done by the public authority paying little mind to its level. They are the public assistance, the turn of events, and the assurance work.

The main thing then, at that point, is the degree to which the public authority can deal with these capacities to deliver labor and products that are conservative, viable, effective, and responsible to all individuals who need them. Also, the public authority is needed to apply the standard of value in leading these capacities. This implies that administration ought to offer types of assistance with no prejudicial way. Administrations are given paying little mind to status, rank, class from the local area. In addition, all individuals from the local area have similar privileges to these administrations under material guidelines.

Albeit the public authority has the capacities as above, it doesn't imply that the public authority should go about as a monopolist in the execution of these capacities. A few pieces of the above capacities can become spaces of obligation in which the public authority appoints the execution to the private area or by utilizing an organization design between the public authority and the private area. The organization between the public authority and the private area in offering different types of assistance to the local area is in accordance with rehashing government.

The government has the responsibility to ensure the fulfillment of rights and obligations of each individual in the health sector as has been regulated in the provisions of Articles 14-20 of Law Number 36 the Year 2009 on Health.[8] The government's responsibilities are in terms of the following:

a. Arranging, directing, sorting out, cultivating, and regulating the execution of wellbeing endeavors that are fair and reasonable by the local area.

b. The accessibility of the climate, course of action, wellbeing offices in both physical and social for the local area to accomplish the most elevated wellbeing level. 
c. The accessibility of assets in the wellbeing area that is reasonable and evenhanded for the whole local area to acquire the most significant level of wellbeing.

d. The accessibility of admittance to data, schooling, and wellbeing administration offices to improve and keep up with the most significant level of wellbeing.

e. Engage and empower the dynamic job of the local area in all types of wellbeing endeavors.

f. The accessibility of all types of value, protected, proficient, and reasonable wellbeing endeavors.

g. The execution of general health care coverage through the public federal retirement aide framework for individual wellbeing endeavors under the arrangements of the enactment.

To do these obligations, the public authority does as such base on the standards of humankind, balance, benefits, security, regard for privileges and commitments, equity, sex and non-segregation, and strict standards.

In the interim, the right to wellbeing and clinical benefits, which show restraint freedoms, is a more explicit piece of the right to wellbeing. It has turned into an agreement in the Indonesian constitution that wellbeing right is a crucial common freedom. The essential way of thinking of ensuring the right to wellbeing as a common freedom is the raison d'etre of human respect.[9]

Wellbeing is a key right of each person. In this manner, each person, family, and local area has the option to acquire assurance for their wellbeing, and the public authority is liable for directing and ensuring so the local area's all in all correct to a sound life is satisfied, including the helpless who can't manage the cost of it. To guarantee the satisfaction of the right to wellbeing, the 1945 Constitution of the Republic of Indonesia, Article 34 passage (3) underlines that: "The state is liable for the arrangement of wellbeing administration offices ...". Article $28 \mathrm{H}$ section (3) specifies that: "Everybody has the privilege to federal retirement aide which permits his full advancement as a noble individual". The arrangements of Article $28 \mathrm{H}$ passage (3) are identified with Article 34 section (2) that peruses: "The state fosters a federal retirement aide framework for all individuals and engages the powerless and unable under human nobility."

Attendants, as experts, are capable and approved to furnish nursing administrations freely and team up with wellbeing laborers in accordance with their position, particularly identified with the extent of nursing practice. The social fact is that the unequal distribution of doctors in rural areas has resulted in nursing staff carrying out medical interventions instead of nursing interventions, considering nurses as the foremost health workers in health services in the community.

Health enhancement assists communities in developing resources to maintain or improve their health and well-being. The health goal to be realized is to achieve optimal health status. The focus of health enhancement is directed to maintain or improve the general health of individuals, families, and communities. Nursing services cover the entire human life cycle, meaning that nursing care is provided since a person is in the womb until a person dies. Therefore, it is known as midwifery nursing, pediatric nursing, nursing for the elderly, and others. The development of a wider field of the health law will be followed by the expansion of nursing authority and responsibility rights in the context of the growth of mandatory medical record law and informed consent. Therefore, nursing service's enhancement demand must be balanced with an increase in qualified nursing health personnel resources. Moreover, the broader duties of the nursing profession are necessary to anticipate with an understanding of the sub-field of nursing law (nursing law) following health growth (health law), both nationally and internationally. 
For medical attendants themselves with respect to the legitimate insurance they have and a few laws as expressed in Article 36 point (a) of Law No. 38 of 2014 on nursing clarifies, "nurture in completing nursing practice reserve the privilege to acquire legitimate assurance as long as they do their obligations adhering to the arrangements of the law, administration guidelines, proficient norms, standard working methods, and arrangements of laws and guidelines." These principles are important for the oppressive lawful security, to be specific an assurance given by the nation to all gatherings to execute their lawful freedoms and law interests in their ability as lawful subjects.

A health worker who does not conduct his work following standard operating procedures and medical procedures means that he has made an error or omission. In addition, it can result in prosecution under criminal law, also be sued for civil compensation if the patient suffers a loss. Prosecution of criminal liability can only be carried out if the patient suffers from permanent disability or dies. Meanwhile, a civil lawsuit can be made if the patient suffers a loss, even though it is from a minor error. Nurses in conducting their work must be guided and based on normative instruments that apply to them.

\section{Conclusion}

The position or status of medical caretakers in clinics is an individual from the Nursing Committee, a non-underlying emergency clinic association, that has the essential capacity of keeping up with and working on the demonstrable skill of nursing staff through certification components, keeping up with proficient quality, and keeping up with proficient morals and discipline. In the hospital, in the delegation of medical actions by doctors to nurses, several conditions must be met and the patient must be guaranteed to receive help on the doctor's responsibility but must meet the existing requirements. The delegation of authority for medical actions from doctors to nurses can only be done in writing per Article 32 Point (1) of Law no. 38 of 2014 concerning Nursing. Delegative delegation can only be delegated to nurses who have the appropriate competencies required. Also, the mandated delegation is given to nurses under supervision. The legitimate security that controls medical caretakers is Law no. 36 of 2009 concerning Health, Article 27 of Law no. 36 of 2009 section (1) on wellbeing laborers are qualified for remuneration and lawful security in doing their obligations following their calling, Minister of Health Regulation number 148 of 2010 on Nursing Practices, and Law no. 38 of 2014 concerning Nursing Article 36 point (a) on Nursing. These principles are essential for the oppressive lawful assurance, to be specific an assurance given by the nation to all gatherings to execute their legitimate freedoms and law interests in their ability as lawful subjects.

\section{References}

[1] P. Sri, Legal Status of Nurses in Health Service Efforts in Hospitals. Jakarta: Raja Grafindo Persada, 2006.

[2] Ta'adi, Health Law: An Introduction Towards Professional Nurses. Jakarta: Kedokteran EGC, 2009.

[3] "No Title Law Number 36 of 2014 on Health Workers".

[4] F. Arizal, Professional Nurse. Jakarta: Bina Media Perintis, 2010.

[5] M. Abdul Kadir, Law and Legal Research. Bandung: PT. Citra Aditya Bakti., 2015. 
[6] I. M. P. Diantha, "Normative Legal Research Methodology," Teor. Metodol. Penelit. a., 2017.

[7] A. Aziz, Introduction to the Basic Concepts of Nursing. Jakarta: EGC, 2004.

[8] Sekretariat Negara, "Law Number 36 Year 2009 concerning Health.” Jakarta, 2009.

[9] E. Hidayat, "Protection of Human Rights in the Law Country of Indonesia," Asas J. Huk. dan Ekon. Islam, vol. 8, no. 2, pp. 80-87, 2016, [Online]. Available: https://www.neliti.com/publications/56534/perlindungan-hak-asasi-manusia-dalamnegara-hukum-indonesia. 